\title{
Autoimmune encephalitis in the elderly - who to test and what to test for
}

\author{
Dr Sophie Behrman (Oxford Health NHS Foundation Trust) and Dr Belinda Lennox (Oxford \\ University Department of Psychiatry)
}

\begin{abstract}
The awareness and understanding of autoimmune encephalitis is blossoming in neurology and patients are being diagnosed and successfully treated with immunotherapy. The diverse symptomatology associated with autoimmune encephalitis means that patients may present initially to mental health services which are less well equipped to identify and investigate such phenomena. Older adult mental health services are used to managing complexity, but the range of pathologies presenting with unusual symptoms that may mimic autoimmune encephalitis is wide and there is no clear guidance as to when and how to investigate for possible autoimmune encephalitis. This paper examines the evidence supporting investigation and management strategies for patients with possible autoimmune encephalitis presenting to older adult psychiatrists.
\end{abstract}

\section{Summary Box}

\section{What is already known about this subject?}

- Autoimmune encephalitis presents with diverse neurological and psychiatric symptoms

- CNS autoantibodies may be detected in serum and/or CSF and are not always clinically relevant

- Guidelines for investigating and managing autoimmune encephalitis have been developed by neurologists in a general hospital setting and are not always relevant or helpful for psychiatrists

\section{What are the new findings?}

- Autoimmune encephalitis may present in the elderly and be diagnosed by older adult psychiatrists

- Autoimmunity plays a role in many neurodegenerative conditions already managed by older adult psychiatrists (e.g. different types of dementia, stroke).

- A "red flag" system may help older adult psychiatrists consider autoimmune encephalitis in their differential diagnosis and help identify who should be further investigated.

\section{How might it impact on clinical practice in the foreseeable future?}

- A red flag system may mean more older adult mental health patients are investigated and treated for autoimmune encephalitis in a timely fashion. 
- Increased awareness of autoimmune encephalitis in older adult mental health patients may lead to a rise in diagnosis and treatment and an accumulation of evidence relevant to the population.

\section{Introduction}

Discovery of antibodies associated with autoimmune encephalitis has revolutionised neurology. Initially, voltage gated potassium channel (VGKC) antibodies were found to be associated with a form of limbic encephalitis presenting with memory loss, confusion and seizures. This case series of patients (aged 44-79) responded well to immunotherapy and it was postulated that these antibodies may signify a relatively common and potentially treatable form of autoimmune encephalitis [1]. Subsequently VGKC antibodies, in the absence of antibodies to LGI1 and CASPR have shown to be non-specific and not pathogenic [2]. LGI1 and CASPR antibodies bind specifically to subunits of the VGKC complex and are more informative, correlating better to clinical status [3]. Neurologists were also interested in a form of limbic encephalitis associated with ovarian teratoma and in 2007 it was discovered that this was mediated by the NMDA receptor antibody in a small case series of young women (aged 14-44) [4]. Over the following decade, other neurological syndromes and associated antibodies have been described. This paper examines the relevance of autoimmune processes in older adults with what may described as "functional" mental illness.

\section{Autoimmune encephalitis}

Limbic encephalitis was originally identified in the context of viral or paraneoplastic pathology, and more recently as an idiopathic autoimmune illness. Symptoms are neuropsychiatric and varied and develop over the course of several weeks. Diagnostic criteria for autoimmune encephalitis have been established (see Box 1), with additional criteria for specific autoimmune limbic encephalitis (MRI hyperintensities localised to medial temporal lobes, and characteristic EEG activity).

Box $1[5]$

A diagnosis of possible autoimmune encephalitis requires all three of the following:

1) Subacute onset (less than 3 months) of working memory deficits, altered mental status (including altered level of consciousness, lethargy or personality change) or psychiatric symptoms (may include mood changes or hallucinations).

2) At least one of the following:

a. New focal CNS findings

b. Seizures not explained by a previously known seizure disorder

c. CSF pleocytosis (White Blood Cell count of more than 5 cells per cubic $\mathrm{mm}$ )

d. MRI features suggestive of encephalitis

3) Reasonable exclusion of alternative causes

Serum autoantibodies are not a sensitive or specific test for autoimmune encephalitis but the presence of serum antibodies with a relevant clinical history may warrant further 
investigation, such as MRI, EEG and lumbar puncture looking for antibodies in the CSF [5]. Serum and/or CSF may be positive for specific autoantibodies (see Table 1).

\section{Encephalopathy linked to systemic autoimmune disease}

In addition to autoimmune encephalitis, some systemic autoimmune processes may have specific neuropsychiatric effects. For example, Systemic Lupus Erythematosus (SLE) may cause neuropsychiatric symptoms such as cognitive changes, mood disorders and psychosis. Other systemic autoimmune diseases with associated neuropsychiatric symptoms include CNS vasculitis and Behçet's disease [6].

\section{Paraneoplastic encephalitis}

As a rule of thumb, antibodies against cell surface antigens (e.g. NMDA-R, LGI1, CASPR2 etc) are more likely to be idiopathic in origin, but can be paraneoplastic (i.e. associated with malignancy). Autoantibodies to intracellular antigens (e.g. Hu, Ri, CV2/CRMP5, Ma2) are more likely to be paraneoplastic [7] and if found should prompt efforts to search for an underlying malignancy. Malignancies associated with paraneoplastic autoantibodies causing encephalitis include lung carcinoma (particularly small cell), germ cell tumours and thymomas. More detailed explanation of paraneoplastic encephalitis is beyond the scope of this article, but it is worth bearing in mind symptoms and signs of malignancy when assessing an older person who may have features of CNS autoimmunity.

\section{Relevance to psychiatry}

Limbic encephalitis has always been of interest to psychiatrists- the first case descriptions of paraneoplastic encephalitis were in older adults in mental health wards [8]. Many patients with autoimmune encephalitis also initially presented to psychiatrists with symptoms including short-term memory loss, confusion, personality and behavioural change and paranoid thoughts. This has led psychiatrists to wonder if in some cases psychiatric symptoms may be autoimmune-mediated and therefore if immunotherapy may be of value. Investigating autoimmune encephalitis is more of a challenge in psychiatry where investigations such as MRI, EEG and lumbar puncture are harder to obtain and may not be practical depending on the patient's presentation.

The diagnostic criteria for Autoimmune Encephalitis, designed with patients presenting to neurology in mind [5], may overlook patients with psychiatric presentations that do not fit the criteria. This risks disregarding potentially clinically and academically interesting syndromes that may be autoimmune mediated and benefit from immunotherapy. Other names have been proposed such as "synaptic and neuronal autoantibody-associated psychiatric syndromes" (SNAps) [9] or simply "autoimmune psychosis" [10] in an effort to not neglect those which may have an autoimmune-type presentation but without fulfilling all the diagnostic criteria and/or without serum antibodies. As the spectrum of presenting symptoms is so broad, "red flags" to help clinicians identify autoimmunity in a population with psychiatric symptoms have been proposed in order to reduce the time from symptom onset to diagnosis and potential treatment [11]. 
Relevance to older adult psychiatry

Within older adult psychiatry, presentations of "confusion" or cognitive problems are relatively common and may be associated with other relevant features, such as new neurological problems, personality change or psychotic symptoms. In most cases these will just be more unusual presentations of a common pathology, such as Alzheimer's or Vascular Dementia or even a mood disorder with perhaps unrelated neurological deficits. However, autoimmune encephalitis and other CNS autoimmune pathology can also present in later life (note the eldest of the original VGKC antibody case series was aged 79 [1]) and the possibility must be kept in mind.

Whilst NMDAR antibody encephalitis is seen in young people, one group have found that a cohort of older patients with slowly progressing cognitive dysfunction have been found to have serum IgA-NMDAR antibodies, which in vitro have been shown to have a broad action reducing the concentration of NMDA receptors and other synaptic proteins [12]. Typically, IgG antibodies are found in classic NMDA- autoimmune encephalitis, but these patients commonly go on to have some longer-term cognitive deficits, which may be IgA mediated. Case studies of patients with neuropsychiatric symptoms initially appearing to be neurodegenerative, associated with IgA-NMDAR antibodies have shown clinical improvement with immunotherapy and halting of brain atrophy on imaging [12]; this may indicate a cohort of patients who might have previously been diagnosed as having a progressive neurodegenerative disorder may have a potentially treatable underlying autoimmune process, perhaps mediated by or at least correlated with, IgA-NMDAR antibodies. This exciting possibility needs replication and further controlled trials of treatment.

Autoantibodies in general are known to increase with ageing [13] and neurodegeneration [14]. Antibodies to neuronal antigens, such as NMDAR, CASPR2 and Glycine receptors have been found in a minority of patients with spontaneous Creutzfeldt-Jakob disease [15], NMDAR- IgA and IgM antibodies have been found in dementia [16], suggesting that these antibodies may have a role in neurodegeneration. NMDAR antibodies have been also shown to increase in normal ageing and have been found in over $20 \%$ of healthy 80 year olds [17]. The role of pre-existing NMDAR antibodies has been examined in stroke patients, where NMDAR antibodies can be protective or pathological depending on the integrity of the blood brain barrier at the time of the stroke [18]. The role of these antibodies in normal ageing and diseases associated with ageing is clearly complex and multifaceted.

In Alzheimer's disease, various specific antibodies, both pathogenic and protective, have been identified [19]. The role of these antibodies as biomarkers has been investigated, (e.g. antibodies to amyloid- $\beta$ protein and to tau) but they are not yet used in clinical practice. As humans naturally produce neuroprotective antibodies to amyloid- $\beta$ and tau, active or passive immunisation to enhance the action of these antibodies has been proposed as a treatment for Alzheimer's disease. Although promising in in vitro and in mouse models, this has not yet been successful in humans due to severe side effects, but clinical trials are ongoing [19].

A newly discovered autoantibody class, termed "functional autoantibodies" are directed to G-protein coupled receptors (GPCRs) and have been shown to be associated with different 
types of dementia [20]. Patients with vascular and Alzheimer's dementia were shown to have $\alpha 1$ and $\beta 2$ adrenoceptor GPCR autoantibodies, with endothelin A receptor antibodies also being particularly prevalent in vascular dementia. Patients with Dementia with Lewy Bodies tended to lack any GPCR-autoantibodies, suggesting a different underlying pathology [20]. These autoantibodies can be neutralised in vitro with aptamer BC007 which gives hope that these autoantibodies can also be explored as potential therapeutic targets in the future.

Investigating CNS autoimmunity in the elderly presenting with psychiatric symptoms

Who to test?

There is, as yet, no clear guidance as to when to look for serum autoantibodies in patients presenting with psychiatric symptoms. The prevalence of CNS autoimmunity in the elderly mentally unwell population is not well-established, nor is the relevance of auto-antibodies, if present, and if there is any clinical gain in treating positive antibodies. There is the added complication that serum positivity does not always equate to CSF positivity, and patients who have positive serum may have negative CSF and vice versa; this may be due to relative lack of sensitivity in the laboratory tests [21].

A prevalence study in a young population (aged 12-50) presenting with first episode psychosis found that 6 patients (5.3\%) tested positive for serum neuronal autoantibodies. Of these 6, 4 had NMDA-R serum antibodies and went on to have lumbar punctures; 3 of the 4 also were CSF positive (the other 1 showed signs of CSF inflammation). All 4 had a good clinical improvement with immunotherapy [22]. Although this is a small study and in a younger population, it gives weight to the idea that screening for autoantibodies in first episode psychosis may identify patients who will have a good clinical outcome with immunotherapy. It may be that further CSF positive/serum negative patients may have been identified if all patients had had a lumbar puncture.

A number of questions remain however:

- What is the prevalence and clinical significance of autoantibodies in the elderly with first episode psychosis?

- What is the prevalence and clinical significance of autoantibodies in psychiatric presentations other than first episode psychosis in the elderly?

- How does the clinician reconcile the potential risks and distress associated with investigations and potential treatment with potential benefit in an unwell population?

NMDA-R encephalitis is rare in the elderly, so it could be argued that "red flags" in an older adult psychiatric population should be more tailored to other antigens. EEG and CSF studies are rarely done as first-line investigations in elderly psychiatric patients so these are not practical components of a diagnostic tool. Based on these caveats, reviewing the "red" and "yellow" flags suggested by Herken and Pruss [11] leaves the following "red flag" criteria which may prompt an older adult psychiatrist to consider an autoimmune process (see Box 2). 
Box 2 Red flag criteria that may prompt an older adult psychiatrist to consider an autoimmune process (adapted from [11]:

- Epileptic seizures

- Faciobrachial dystonic seizures (associated specifically with LGI1- autoantibodies)

- MRI abnormalities (mediotemporal hyperintensities, atrophy pattern)

- Suspicion of underlying malignancy

- Other autoimmune disease

- Decreased levels of consciousness and/or confusion

- Speech disturbance (dysarthria or aphasia)

- Focal neurological deficits unexplained by other pathologies.

- Movement disorder (e.g. dyskinesia)

- New onset psychotic symptoms

- Atypical decline in cognitive function

- Headache

Investigations

If these red flag criteria are met further investigation is warranted, including EEG, lumbar puncture, MRI and serum antibody testing (see table 2). Additional investigations may be indicated if there is a confirmed or suspicions of a tumour (suggesting a paraneoplastic process) or signs of systemic inflammation (e.g. SLE).

It is worth noting that the specificities and sensitivities of these investigations in an elderly population are not known and the relative increase in likelihood of neurodegenerative conditions may make the results more difficult to interpret.

\section{Management}

The first obstacle for the management of older adults with suspected autoimmune encephalitis may be the setting. The possible behavioural disturbance and suicidality may be best managed on a psychiatric ward, but this may be at the expense of certain investigations and treatments which may only be possible in a general hospital. Good management requires collaboration between neurologists and psychiatrists and patient-specific creative solutions.

The initial management in a psychiatric setting usually involves antipsychotics. There are no guidelines as to particular antipsychotics being more efficacious or better tolerated than other. All antipsychotics carry a risk of extrapyramidal side effects, which are more common in the elderly; patients with NMDA-R encephalitis also seem to have increased susceptibility to antipsychotic-related neuroleptic malignant syndrome [23]. Electroconvulsive therapy (ECT) has been used with good effect in NMDA-R encephalitis, particularly in patients suffering from catatonia [24].

The definitive treatment of autoimmune encephalitis is removal of the circulating antibodies by intravenous immunoglobulins (IVIg) or plasma exchange followed by immunosuppression (steroids, followed by steroid- sparing agents, such as azathioprine or mycophenolate 
mofetil) and progressing as necessary to second-line immunotherapy (rituximab and cyclophosphamide). In paraneoplastic cases, tumour removal is, of course, part of the treatment strategy.

Immunotherapy protocol is based on a large cohort study with cases aged 8 months to 85 years, but skewed towards the younger end of the population [25]. Clinical improvement is seen if immunotherapy is started within the first few weeks of symptoms and the best longterm results were seen in those who progressed to second-line strategies [25]. Younger patients also seem to have a better response to treatment. [26]. It is worth noting that there has not been any comparison of treatment against placebo and few RCTs to guide protocols and no specific examination of treatment strategies in the elderly.

It may be weeks to months before a clinical improvement is seen with immunotherapy [26] and if symptomatic improvement does not occur, it may prompt the clinical team to reconsider the diagnosis. Antibody titres may decrease rapidly with immunotherapy before a clinical improvement is seen or conversely can stay positive for a long time after clinical improvement has occurred. As with all aspects of medicine, emphasis should be put on treating the patient rather than a laboratory measure, but serial antibody titres may be useful in cases of relapse [26]. There is no evidence for long-term antipsychotics in preventing relapse. Relapse is fairly common (20\% of NMDA-R encephalitis) and may occur years after the original illness; risk of relapse is reduced by immunotherapy in the original episode [27].

It is not clear what to do in the subgroup of patients who have antibodies in their serum but not in the CSF. There are case reports of improvements with immunotherapy in some such patients (e.g. [22]) but cases are best discussed with specialist neurologists and psychiatrists.

\section{Conclusions}

There is little evidence guiding diagnosis, investigation and management of autoimmune encephalitis in an adult psychiatric population, and even less evidence in the elderly. It is likely that with time and further research, more specific clinical phenotypes and biomarkers will be established to guide management.

At present, a clinically pragmatic strategy in older adult psychiatry could be to test for specific autoantibodies (see table 1 ) in cases where some red flag symptoms are present (see Box 2). Joint working between neurology and psychiatry may help facilitate MRI, EEG and lumbar puncture and manage the practical risks associated with subsequent immunotherapy.

Although "positive" autoantibody titres may provide hope in clinically complex cases, it is worth ensuring that this doesn't bias judgement. In the elderly, autoantibody titres are less reliable (generally increased with ageing and neurodegeneration) and there is a risk of treating a false (or at least clinically irrelevant) false positive and missing other pathologies.

The concept of autoimmune psychosis demands that clinicians maintain open minds as to the pathological processes behind patients' symptoms and challenges the current 
dichotomy in older adult psychiatry of dividing patients into "functional" and "organic" in presentation. 


\section{Table 1}

\begin{tabular}{|c|c|c|c|c|}
\hline Antigen & $\begin{array}{l}\text { Psychiatric } \\
\text { features }\end{array}$ & $\begin{array}{l}\text { Other key } \\
\text { features }\end{array}$ & $\begin{array}{l}\text { Associated } \\
\text { tumour? }\end{array}$ & $\begin{array}{l}\text { Typical } \\
\text { demographic }\end{array}$ \\
\hline $\begin{array}{l}\text { NMDA } \\
\text { Receptor [28] }\end{array}$ & $\begin{array}{l}\text { Anxiety, } \\
\text { agitation, } \\
\text { delusions, } \\
\text { hallucinations, } \\
\text { catatonia }\end{array}$ & $\begin{array}{l}\text { Seizures } \\
\text { Autonomic } \\
\text { instability } \\
\text { Movement } \\
\text { disorder } \\
\text { Extralimbic } \\
\text { encephalopathy } \\
\text { Seizures } \\
\text { Memory } \\
\text { impairment }\end{array}$ & $\begin{array}{l}\text { Ovarian } \\
\text { teratoma } \\
\text { (sometimes) }\end{array}$ & $\begin{array}{l}\text { Children and } \\
\text { young women. }\end{array}$ \\
\hline VGKC & \multicolumn{4}{|c|}{$\begin{array}{l}\text { Not sufficiently specific. Replaced by testing antibodies to CASPR and } \\
\text { LGI1, subunits of the potassium channel. Patients may be positive to } \\
\text { LGI1 and/or CASPR2, and in rare cases may have a relevant history, } \\
\text { VGKC antibodies and negative to both LGI1/CASPR [29]; usually VGKC } \\
\text { positivity in the absence of LGI1 and CASPR2 is not a good marker for a } \\
\text { CNS autoimmune process and is not clinically relevant. [2] }\end{array}$} \\
\hline $\begin{array}{l}\text { LGI1 and/or } \\
\text { CASPR2 [29] }\end{array}$ & $\begin{array}{l}\text { Confusion. } \\
\text { Personality } \\
\text { change. } \\
\text { Hallucinations }\end{array}$ & $\begin{array}{l}\text { Faciobrachial } \\
\text { dystonic } \\
\text { seizures. } \\
\text { Autonomic } \\
\text { dysfunction } \\
\text { (especially } \\
\text { hyperhidrosis). } \\
\text { Weight loss. } \\
\text { Insomnia } \\
\end{array}$ & Rare, thymoma & $\begin{array}{l}\text { More likely } \\
\text { men. Late } \\
\text { middle age (31- } \\
84) \text { [2] }\end{array}$ \\
\hline AMPAR [30] & $\begin{array}{l}\text { Amnesia } \\
\text { confusion, } \\
\text { agitation, } \\
\text { psychosis, } \\
\text { affective } \\
\text { symptoms }\end{array}$ & Seizures, & $\begin{array}{l}\text { Breast, lung } \\
\text { cancer, } \\
\text { thymoma }\end{array}$ & $\begin{array}{l}\text { Women twice } \\
\text { as likely as } \\
\text { men. Age range } \\
\text { 14-92, mean } 53\end{array}$ \\
\hline $\begin{array}{l}\text { GABA-AR } \\
{[31]}\end{array}$ & $\begin{array}{l}\text { Varied } \\
\text { symptoms of } \\
\text { encephalopathy. } \\
\text { Cognitive } \\
\text { dysfunction. }\end{array}$ & $\begin{array}{l}\text { Seizures. } \\
\text { Multifocal brain } \\
\text { lesions on } \\
\text { imaging. Good } \\
\text { response to } \\
\text { immunotherapy }\end{array}$ & Thymoma. & $\begin{array}{l}\text { Few cases } \\
\text { described, } \\
\text { many in } \\
\text { children. Age } \\
\text { range } 1-71 \text {, } \\
\text { mean } 44 .\end{array}$ \\
\hline $\begin{array}{l}\text { GABA-BR } \\
{[32]}\end{array}$ & $\begin{array}{l}\text { Limbic } \\
\text { encephalitis. } \\
\text { Cognitive } \\
\text { changes (rapidly } \\
\text { progressive }\end{array}$ & $\begin{array}{l}\text { Seizures. Often } \\
\text { refractory. }\end{array}$ & $\begin{array}{l}\text { Small cell lung } \\
\text { cancer in } 50 \%\end{array}$ & $\begin{array}{l}\text { Median age } 66 \\
\text { (range } 44-85 \text { ) }\end{array}$ \\
\hline
\end{tabular}




\begin{tabular}{|l|l|l|l|l|}
\hline & $\begin{array}{l}\text { dementia) } \\
\text { Behavioural } \\
\text { changes. }\end{array}$ & & & \\
\hline
\end{tabular}

Table 2: Investigations in autoimmune encephalitis

\begin{tabular}{|c|c|c|}
\hline Investigation & Expected results in Autoimmune encephalitis & Notes \\
\hline \multirow[t]{2}{*}{ EEG } & $\begin{array}{l}\text { Focal or diffuse slow activity }+/ \text { - foci of } \\
\text { epileptic activity (subclinical seizures) [11] }\end{array}$ & \\
\hline & $\begin{array}{l}\text { Extreme delta brush pattern more specific and } \\
\text { associated with worse outcome and increased } \\
\text { likelihood of ICU admission [33] }\end{array}$ & \\
\hline \multirow[t]{2}{*}{$\mathrm{MRI}$} & $\begin{array}{l}\text { Unilateral or bilateral hippocampal MRI FLAIR- } \\
\text { T2 hyperintensities (typical of limbic } \\
\text { encephalitis) [5] }\end{array}$ & \multirow{2}{*}{$\begin{array}{l}\text { Not a sensitive } \\
\text { investigation, even } \\
\text { when marked } \\
\text { neurological } \\
\text { component. [34]. More } \\
\text { useful for excluding } \\
\text { other diagnoses } \\
\text { (dementia, } \\
\text { demyelinating } \\
\text { conditions, vasculitis, } \\
\text { tumour etc.) particularly } \\
\text { in the elderly where } \\
\text { these pathologies are } \\
\text { more common. }\end{array}$} \\
\hline & $\begin{array}{l}\text { Transient contrast enhancement in medial } \\
\text { temporal lobe(s) (especially in paraneoplastic } \\
\text { encephalitis) [5] }\end{array}$ & \\
\hline${ }^{18}$ F-FDG-PET & Medial temporal lobe hypermetabolism. [35] & $\begin{array}{l}\text { May be more sensitive } \\
\text { than MRI but lower } \\
\text { specificity. [36] }\end{array}$ \\
\hline \multirow[t]{3}{*}{ CSF } & $\begin{array}{l}\text { Pleocytosis (6-14 cells/ } \mu \text { l) (may be earlier sign) } \\
\text { [37] }\end{array}$ & \multirow{3}{*}{$\begin{array}{l}\text { CSF antibodies are more } \\
\text { relevant than serum } \\
\text { (higher sensitivity and } \\
\text { specificity, better } \\
\text { correlation to clinical } \\
\text { course with treatment) } \\
\text { [21] }\end{array}$} \\
\hline & Oligoclonal bands (may be later sign) [37] & \\
\hline & Specific autoantibodies & \\
\hline $\begin{array}{l}\text { Whole body } \\
\text { PET/CT +/- US } \\
\text { testes/ovaries }\end{array}$ & $\begin{array}{l}\text { To look for a tumour if a paraneoplastic } \\
\text { process suspected. }\end{array}$ & \\
\hline ANA & Non-specific marker of systemic inflammation & \\
\hline
\end{tabular}

\section{References}


[1] A. Vincent, C. Buckley, J. Schott and e. al., "Potassium channel antibody-associataed encephalopathy: a potentially immunotherapy responsive form of limbic encephalitis," Brain, vol. 127, no. 3, pp. 701-712, 2004.

[2] A. van Sonderen, M. Schreurs, M. de Brujin and e. al., "The relevance of VGKC positivity in the absence of LGI1 and Caspr2 antibodies," Neurology, vol. 86, no. 18, pp. 1692-1699, 2016.

[3] B. Lang, M. Makuch, T. Moloney and e. al., "Intracellular and non-neuronal targets of voltage-gated potassium channel complex antibodies.," J Neurol Neurosurg Psychiatry, vol. 88, pp. 353-361, 2017.

[4] J. Dalmau, E. Tuzun and H. e. a. Wu, "Paraneoplastic anti-N-methyl-D-aspartate receptor encephalitis associated with ovarian teratoma," Ann. Neurol., vol. 61, no. 1, pp. 25-36, 2007.

[5] F. Graus, M. Titulaer, R. Balu and e. al., "A clinical approach to diagnosis of autoimmune encephalitis," Lancet Neurology, vol. 15, pp. 391-404, 2016.

[6] M. Kayser and J. Dalmau, "The emerging link between autoimmune disorders and neuropsychiatric disease," Journal of Neuropsychiatry and Clinical Neuroscience, vol. 23, no. 1, pp. 90-97, 2011.

[7] G. Ricken, C. Schwaiger, D. de Simoni and e. al., "Detection methods for autoantibodies in suspected autoimmune encephalitis," Neurology, vol. 9, no. 841, pp. 1-12, 2018.

[8] J. Brierley, J. H. R. Corsellis and e. al., "Subacute encephalitis of later adult life mainly affecting the limbic areas," Brain, vol. 83, no. 3, pp. 357-370, 1960.

[9] A. Al-Diwani, T. Pollak, A. Langford and e. al., "Synaptic and neuronal autoantibodyassociated psychiatric syndromes: controversies and hypotheses," Frontiers in Psychiatry, vol. 8, no. 13, pp. 1-11, 2017.

[10] S. Najjar, J. Steiner, A. Najjar and e. al, "A clinical approach to new-onset psychosis associated with immune dysregulation: the concept of autoimmune psychosis," Journal of Neuroinflammation, vol. 15, p. 40, 2018.

[11] J. Herken and H. Pruss, "Red flags: clinical signs for identifying autoimmune encephalitis in psychiatric patients," Frontiers in Psychiatry, vol. 8, p. 25, 2017.

[12] H. Pruss, M. Holtje, N. Maier and e. al., "IgA NMDA receptor antibodies are markers of synaptic immunity in slow cognitive impairment," Neurology, vol. 78, pp. 1743-1753, 2012.

[13] Y. Richaud-Patin and A. Villa, "Autoantibodies, mortality and Ageing," Medical Hypotheses, vol. 44, pp. 10-15, 1995.

[14] J. Terryberry, G. Thor and J. Peter, "Autoantibodies in Neurodegenerative Diseases: antigen-specific frequencies and intrathecal analysis," Neurobiology of Aging, vol. 19, no. 3, pp. 205-216, 1998.

[15] M. Rossi, S. Mead, J. Collinge and e. al., "Neuronal antibodies in patients with suspected or confirmed sporadic Creutzfeldt-Jakob disease," Journal of Neurology, Neurosurgery and Psychiatry, vol. 86, pp. 692-694, 2014.

[16] S. Doss, K.-P. Wandinger, B. Hyman and e. al, "High prevalence of NMDA receptor IgA/IgM antibodies in different dementia types," Annals of Clinical and Translational Neurology, vol. 1, no. 10, pp. 822-832, 2014. 
[17] H. Ehrenreich, "Autoantibodies against the N-Methyl-D-Aspartate Receptor Subunit NR1: untangling apparent inconsistencies for clinical practice," Frontiers in Immunology, vol. 8, p. 181, 2017.

[18] M. Zerche, K. Weissenborn, C. Ott, E. Dere, A. Asif, H. Worthmann, I. Hassouna, K. Rentzsch, A. Truc, L. J. Dahm, L. Binder, J. Wiltfang, A.-L. Siren, W. Stocker and H. Ehrenreich, "Preexisting serum autoantibodies against the NMDAR subunit NR1 modulate evolution of lesion size in acute ischemic stroke.," Stroke, vol. 46, pp. 11801186, 2015.

[19] J. Wu and L. Li, "Autoantibodies in Alzheimer's Disease: potential biomarkers, pathogenic roles and therapeutic implications," Journal of Biomedical Research, vol. 30, no. 5, pp. 361-372, 2016.

[20] G. P. H. M. J. e. a. Wallukat, "Functional autoantibodies in patients with different forms of dementia," PLOS ONE, vol. 13, no. 3, p. e0192778, 2018.

[21] J. Masdeu, "Detecting synaptic autoantibodies in psychoses: need for more sensitive methods," vol. 30, no. 1, pp. 317-326, 2017.

[22] J. Scott, D. Gillis, A. Ryan and e. al., "The prevalence and treatment outcomes of antineuronal antibody-positive patients admitted with first episode of psychosis," BJPsych Open, vol. 4, no. 2, pp. 69-74, 2018.

[23] F. Lejuste, F. Thomas, G. Picard and e. al., "Neuroleptic intolerance in patients with anti-NMDAR encephalitis," Neurology, Neuroimmunology, and Neuroinflammation., vol. 3, p. e280, 2016.

[24] N. Warren, V. Grote, C. O'Gorman and e. al., "Electroconvulsive therapy for anti-Nmethyl-D-aspartate (NMDA) receptor encephalitis: a systematic review of cases," Brain Stimulation, vol. 12, pp. 329-334, 2019.

[25] M. Titulaer, L. McCracken, I. Gabilondo and e. al., "Treatment and prognostic factors for long-term outcome in patients with anti-NMDA receptor encephalitis: an observational cohort study," Lancet Neurology, vol. 12, pp. 157-165, 2013.

[26] M. Platt, D. Agalliu and T. Cutforth, "Hello from the other side: how autoantibodies circumvent the blood-brain barrier in autoimmune encephalitis.," Frontiers in Immunology, vol. 8, p. 442, 2017.

[27] I. Gabilondo, I. Saiz, V. Galan and e. al., "Analysis of relapses in anti-NMDAR encephalitis," Neurology, vol. 77, no. 10, pp. 996-999, 2011.

[28] S. Irani, A. Vincent and J. Schott, "Autoimmune Encephalitis," BMJ, vol. 342, p. d1918, 2011.

[29] S. Binks, C. Klein, P. Waters and e. al., "LGI1, CASPR2 and related antibodies: a molecular evolution of the phenotypes," Journal of Neurology, Neurosurgery and Psychiatry, vol. 89, pp. 526-534, 2018.

[30] O. Laurido-Soto, M. Brier, L. Simon and e. al., "Patient characteristics and outcome associations in AMPA receptor encephalitis," Journal of Neurology, vol. 266, pp. 450460, 2019.

[31] K. O'Connor, P. Waters, L. Komorowski and e. al., "GABA-A receptor autoimmunity. A multicenter experience," Neurology: Neuroimmunology and Neuroinflammation, vol. 6, no. 3, pp. 1-6, 2019. 
[32] M. van Coevorden-Hameete, M. de Bruijn, E. de Graaff and e. al, "The expanded clinical spectrum of anti-GABABR encephalitis and added value of KCTD16 autoantibodies," Brain, vol. 142, pp. 1631-1643, 2019.

[33] L. Gillinder, N. Warren, G. Hartel and e. al., "EEG findings in NMDA encephalitis- a systematic review," Seizure: European journal of epilepsy, vol. 65, pp. 20-24, 2019.

[34] B. Kelley, S. Patel, H. Marin and e. al., "Autoimmune encephalitis: pathophysiology and imaging review of an overlooked diagnosis," American Journal of Neuroradiology, vol. 38, pp. 1070-1078, 2017.

[35] S. Morbelli, M. Djekidel, S. Hesse and e. al., "Role of 18F-FDG-PET imaging in the diagnosis of autoimmune encephalitis," Lancet Neurology, vol. 15, p. 1009, 2016.

[36] F. Graus and J. Dalmau, "Author's reply: Role of 18F-FDG-PET imaging in the diagnosis of autoimmune encephalitis," Lancet Neurology, vol. 15, p. 1010, $2016 \mathrm{a}$.

[37] T. Oviedo-Salcedo, L. de Witte, T. Kumpfel and e. al., "Absence of cerebrospinal fluid antineuronal antibodies in schizophrenia spectrum disorders," British Journal of Psychiatry, vol. 212, pp. 318-320, 2018. 